\title{
Protective Effect of an Edible Tomato Plant Extract/Chitosan Coating on the Quality and Shelf Life of Sierra Fish Fillets
}

\author{
H. E. Ramírez-Guerra, ${ }^{1}$ F. J. Castillo-Yañez ${ }^{1},{ }^{1}$ E. A. Montaño-Cota, ${ }^{1}$ \\ S. Ruíz-Cruz, ${ }^{2}$ E. Márquez-Ríos, ${ }^{1}$ D. F. Canizales-Rodríguez, ${ }^{1}$ W. Torres-Arreola, ${ }^{1}$ \\ N. Montoya-Camacho, ${ }^{1}$ and V. M. Ocaño-Higuera $\mathbb{D}^{1}$
}

${ }^{1}$ Universidad de Sonora, Blvd. Encinas y Rosales s/n., Col. Centro, 83000 Hermosillo, SON, Mexico

${ }^{2}$ Instituto Tecnológico de Sonora, 5 de Febrero 818 Sur, Col. Centro, Obregón, SON, Mexico

Correspondence should be addressed to V. M. Ocaño-Higuera; victor.ocano@unison.mx

Received 24 November 2017; Accepted 7 March 2018; Published 6 May 2018

Academic Editor: Ana B. Martin-Diana

Copyright (C) 2018 H. E. Ramírez-Guerra et al. This is an open access article distributed under the Creative Commons Attribution License, which permits unrestricted use, distribution, and reproduction in any medium, provided the original work is properly cited.

\begin{abstract}
The products of fishing are highly perishable foods. Thus, it is necessary to seek viable alternatives that help to preserve product freshness and quality and to increase its shelf life. One of these alternatives is the use of extracts with antimicrobial activity obtained from plants, such as tomato, which has been observed to present compounds with antimicrobial activity. The objective of this work was to determine the effect of an extract obtained from the tomato plant and incorporated into an edible chitosan coating on the quality and shelf life of the sierra fish fillet stored on ice for 15 days. For the latter, an extract was prepared with dehydrated tomato plants, which was incorporated by immersion alone or in combination with an edible chitosan-based coating in sierra fish fillets. The following treatments were applied: C (Chitosan), TPE (Tomato Plant Extract), TPE-C (TPE-Chitosan), and control (without chitosan and extract). Color, $\mathrm{pH}$, WHC, ATP-related compounds, and $K$ value were monitored during 15 days of storage on ice. Likewise, the total count of mesophiles was determined. The results indicated that treatments C, TPE, and TPE-C were significantly different $(p<0.05)$ from lot control in terms of the concentration of ATP-related compounds, $K$ value, $\mathrm{pH}$, and total mesophilic count. We concluded that application of the extract alone or in combination with chitosan allows for the improvement of the quality and shelf life of the sierra fish fillet.
\end{abstract}

\section{Introduction}

It is well known that seafood products are more susceptible to deterioration than, for example, beef; therefore, the application of preservation methods to maintain their freshness and microbiological safety, as well as their nutritional quality after catching, becomes crucial. Thus, refrigeration and freezing are two common preservation methods applied for these purposes. However, currently, seafood distributors have been exploring novel and reliable alternatives in order to delay bacterial growth and also contribute to preserving the freshness and quality of these products. Edible films are an example of these new seafood preservation methods. It has been manufactured that edible coatings have been manufactured with incorporated antimicrobial agents, which can reduce spoilage events by enhancing the shelf life of seafood products. These coating films have been prepared with several organic compounds such as lipids, proteins, and polysaccharides that have great potential use in preserving fresh fish fillets [1]. Therefore, chitosan has been largely employed in the manufacture of coating film. Chitosan is a biopolymer derived from the chitin contained in shrimp shell. Chitosan properties are very useful in making edible coating films because of their good gel-forming capacity and also because chitosan is safe for human consumption [2]. On the other hand, extracts of plants such as tomato have been employed to delay microbial growth; it has been reported that tomato plant extracts contain certain antimicrobial compounds. Therefore, the aim of the present research was to evaluate the effect of a tomato (Solanum lycopersicum) 
plant extract incorporated into a chitosan edible coating on the freshness, quality, and shelf life of sierra (Scomberomorus sierra) fish fillets stored on ice during 15 days.

\section{Materials and Methods}

2.1. Sierra Fillets. Sierra (Scomberomorus sierra) specimens, weighing $1.21 \pm 0.16 \mathrm{~kg}$ and $61.9 \pm 2.76 \mathrm{~cm}$ in length, were captured in Kino Bay, Sonora, Mexico. After being caught, the specimens were stored on ice and immediately transported to the Food Research Laboratory at Sonora University in Hermosillo, Sonora, Mexico. Once in laboratory, the sierra specimens were manually eviscerated and filleted.

2.2. Preparation of the Tomato Plant Extract. The tomato plant extract was prepared according to the procedure described by Silva-Beltrán et al. [3]. Thirty-five mg of dry tomato plant was mixed with a $280 \mathrm{~mL}$ ethanol/acetic acid $(95: 5, \mathrm{v} / \mathrm{v})$ solution. After $72 \mathrm{~h}$ of maceration under constant stirring and darkness, the mixture was filtered using a Whatman cellulose paper filter. The crude extract was concentrated by rotoevaporation and then stored at $-20^{\circ} \mathrm{C}$ until its use.

2.3. Preparation and Application of Edible Coating. Emulsions were prepared by dissolving chitosan $(1 \%, \mathrm{w} / \mathrm{v})$ in acetic acid $(1 \%, \mathrm{v} / \mathrm{v})$ and glycerol $(0.5 \%, \mathrm{v} / \mathrm{v})$ as a plasticizer. The mixture was homogenized at 17,500 rpm for $3 \mathrm{~min}$ (Chitosan treatment, C). Later, tomato plant extract (TPE) at concentration of $0.3 \%(\mathrm{v} / \mathrm{v})$ was incorporated and homogenized as previously described (treatment TPE-C). Another treatment was TPE at $0.3 \%(\mathrm{v} / \mathrm{v})$ and lot control (without $\mathrm{C}$ and TPE). Finally, the edible coatings were formed by immersing the sierra fillets in these solutions for two min. After the treatments were applied, all sierra fillets were placed into plastic bags prior to storage-on-ice.

2.4. Ice-Storage Experiment. The storage-on-ice of sierra fillets was carried out during 15 days. Shear force, $\mathrm{pH}$, color, Water-Holding Capacity (WHC), Adenosine TriPhosphate (ATP) and its degradation products, and $K$ index were evaluated at $0,3,6,9,12$, and 15 days. In addition, mesophile growth was evaluated at $0,5,10$, and 15 days.

\subsection{Analytical Procedures}

2.5.1. ATP-Degradation Products and $K$ Index. Adenosine TriPhosphate (ATP) and its degradation products up to Hypoxanthine (Hx) were assessed by High-Performance Liquid Chromatography (HPLC) according to Ryder [4]. After quantification of these compounds, the $K$ index was established by employing the equation described by Sagedhal et al. [5] as follows: $K$ value $=[(\mathrm{HxR}+\mathrm{Hx}) /(\mathrm{ATP}+\mathrm{ADP}+$ $\mathrm{AMP}+\mathrm{IMP}+\mathrm{HxR}+\mathrm{Hx})] \times 100$.

2.5.2. $\mathrm{pH}$, Texture, $\mathrm{WHC}$, and Color. $\mathrm{pH}$ determination was developed in agreement with the methodology proposed by Woyewoda et al. [6], utilizing a precalibrated digital (Thermo Electron Co.; Orion 420 A) potentiometer. Texture analysis of muscle was performed using a Shimadzu model EZ-S Shimadzu 346-54909-33 texturometer (Kyoto,
Japan), equipped with a Warner-Bratzler cell. Water-Holding Capacity (WHC) was measured according to the methodology proposed by Cheng et al. [7] employing the following equation: \% CRA $=100-((W i-W f) / W i \times 100)$, where $W_{i}=$ initial weight and $W_{f}=$ weight of fillet after centrifugation and drying of the released water. Finally, color evaluation was developed using tristimulus colorimetry, employing a MiniScan Hunter Lab (Reston, VA, USA) colorimeter. $L, a^{*}$, and $b^{*}$ values were recorded.

2.5.3. Total Count of Aerobic Mesophylls. The count of mesophiles present in sierra muscle was developed according to the methodology described in the Official Mexican Norm Regulation NOM-092-SSA1-1994 [8].

2.6. Statistical Analysis. Collected data were analyzed using Analysis Of VAriance (ANOVA) employing the NCSS (ver. 6.0.22) statistical software package. A Tukey-Kramer test was utilized when significant differences $(p<0.05)$ were detected between the means. The mesophile count was repeated twice $(n=2)$, and the remainder of the analytical determinations, four times $(n=4)$.

\section{Result and Discussion}

3.1. ATP Degradation. ATP degradation in muscle from aquatic species has been considered as one of the most significant postmortem changes. In Figure 1, it can be observed that the initial ATP concentrations in control (untreated) sierra fillets, as well as in those corresponding to each treatment (C, TPE, and TPE-C), were lower than $0.24 \mu \mathrm{mol} / \mathrm{g}$. It is well known that certain ATP concentrations can be depleted by the struggle while being caught. Castillo-Yáñez et al. [9] reported similar ATP values in the same sierra (Scomberomorus sierra) fish species. With respect to storage time on ice (15 days), no significant changes were observed among treatments C, TPE, TPE-C, and control. The ATP degradation pattern in sierra fillets was similar to those reported in other fish species.

Independently of the treatment applied sierra fillets, a rapid ATP conversion into Inosine MonoPhosphate (IMP) was recorded. IMP was mainly predominated in sierra muscle throughout the ice-storage experiment, exhibiting concentrations within the ranges of $9.10 \pm 0.80$ and $10.30 \pm$ $0.10 \mu \mathrm{mol} / \mathrm{g}$. Then, the IMP was slowly degraded into HxR and $\mathrm{Hx}$, in which this behavior has been correlated with loss-of-freshness in some fish species. The ATP concentration remained similar $(p \geq 0.05)$ among control and treatments during the ice-storage experiment. In contrast, IMP concentration in control decreased significantly $(p<0.05)$, whereas HxR and Hx increased ( $p<0.05)$, respectively. The previously mentioned behavior can be associated with the initial phase of bacterial growth [10].

3.2. $K$ Value. $K$ value determination has been utilized to measure the quality of several seafood products. Lower $K$ values indicate high freshness of the product. In Figure 2(a), the $K$ values are presented of sierra fillets (treatments and control) stored on ice during 15 days. Initial $K$ values for 


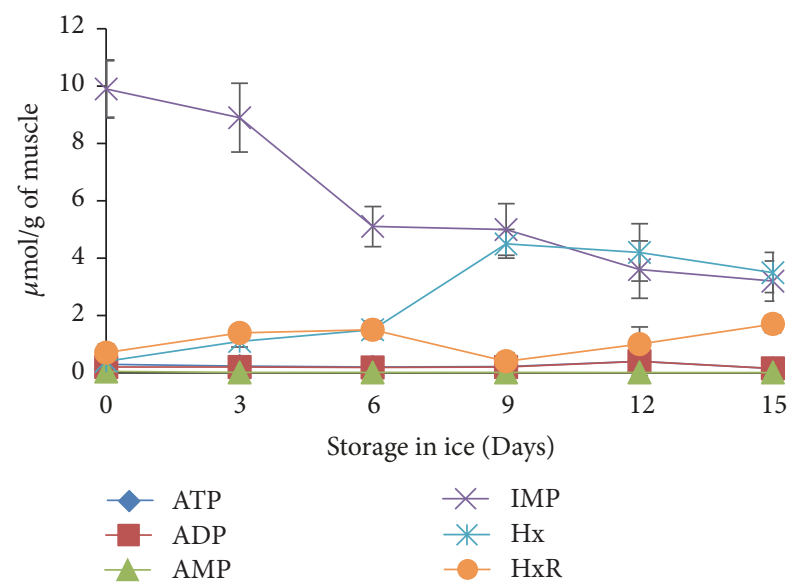

(a)

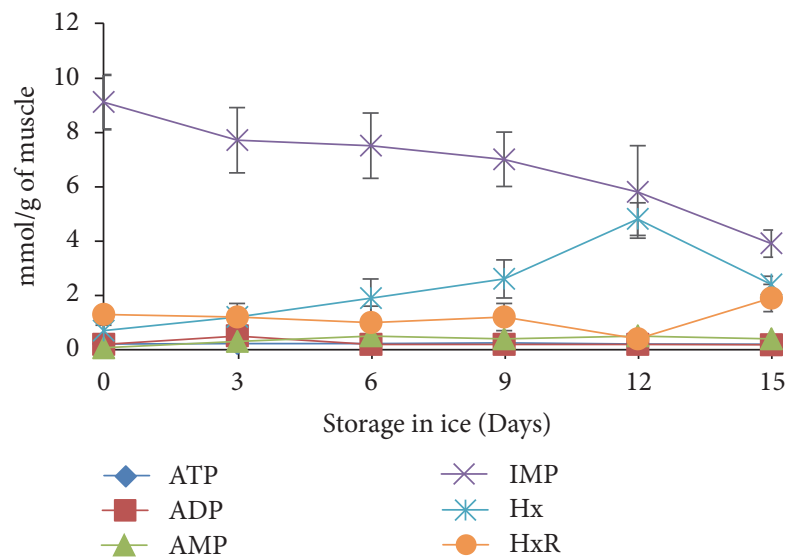

(c)

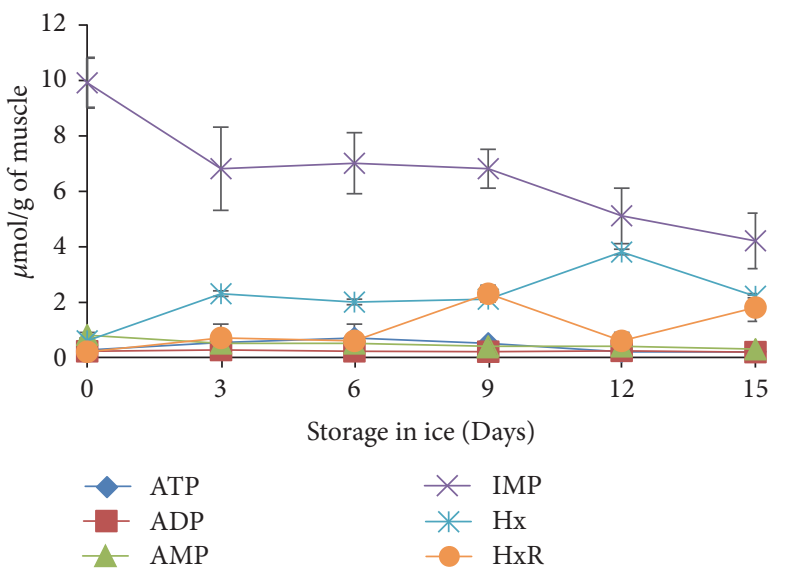

(b)

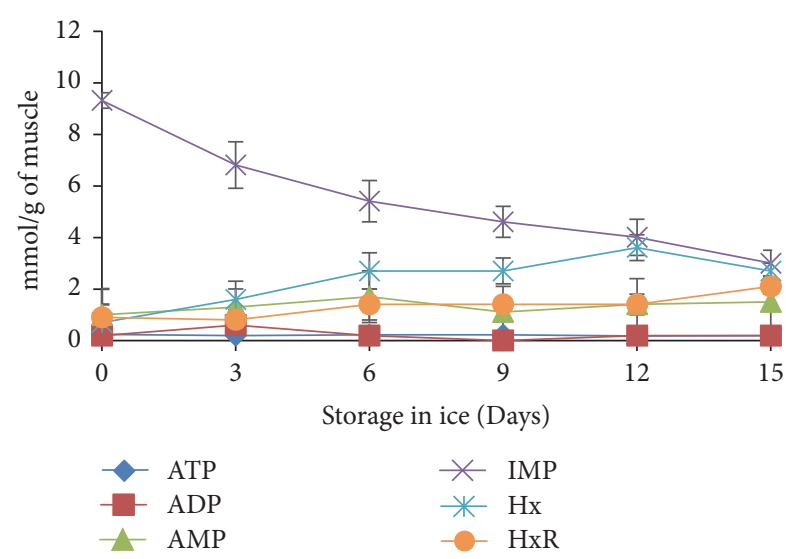

(d)

FIGURE 1: Concentration of ATP, ADP, AMP, IMP, HxR, and Hx in fillets of sierra (Scomberomorus sierra) with different treatments: (a) control, (b) tomato plan extract, (c) chitosan, and (d) tomato plant extract-chitosan, stored during 15 days in ice. The values are the average of $n=4 \pm$ the standard deviation. The concentrations of ATP, ADP, and AMP were not affected by the treatments and the storage time on ice ( $p \geq 0.05)$, while the concentration of IMP, Hx, and HxR was affected by the treatments and storage time $(p<0.05)$.

control, TPE-C, C, and TPE were 9.52 $\pm 2.51 \%, 12.97 \pm 2.83 \%$, $13.27 \pm 2.02 \%$, and $9.58 \pm 2.17 \%$, respectively. $K$ values in control, TPE-C, C, and TPE constantly increased $(p<0.05)$ throughout time storage (from 0 to 15 days), demonstrating final values of $59.70 \pm 4.00 \%, 49.53 \pm 2.79 \%, 47.89 \pm 5.46 \%$, and $44.95 \pm 3.78 \%$, respectively. In this manner, the control ( $y$ $\left.=3.45 x+11.98 ; R^{2}=0.97\right)$ showed the highest increment in $K$ value, differing significantly $(p<0.05)$ from those in the TPE-C, C, and TPE treatments and coinciding with the ATP degradation course. The previously registered $K$ values were lower than those reported by Castillo-Yáñez et al. [9] from sierra (Scomberomorus sierra) muscle (80.6\%).

3.3. $p H$. The fishery industry has considered $\mathrm{pH}$ measurement as an important parameter associated with fish freshness. Figure 2(b) depicts $\mathrm{pH}$ behavior in sierra fillets (control and treatments) stored on ice during 15 days. Control sierra fillets exhibited a higher $\mathrm{pH}$ value $(6.52 \pm 0.09, p<$ $0.05)$ in comparison to those registered in TPE-C $(6.24 \pm$ $0.05), C(6.25 \pm 0.08)$, and TPE $(6.14 \pm 0.05)$ prior to the ice-storage experiment. It is possible that the acetic acid used to solubilize chitosan and TPE prior to treatment (TPE-C, C, and TPE) application on sierra fillets exerted an influence on the decrease in $\mathrm{pH}$. On the other hand, a significant $(p<$ 0.05 ) increase in $\mathrm{pH}$, from $6.52 \pm 0.09$ to $6.81 \pm 0.0 .06$, on ice-stored control fillets after 15 days was recorded, finding that the control lot was significantly different from the $\mathrm{C}$, TPE, and TPE-C treatments. The increase in $\mathrm{pH}$ could be associated with the formation of volatile compounds, such as ammonia and amines (histamine, putrescine, cadaverine, and tyramine), produced in autolytic pathways, as well as by bacterial action on free amino acids [11].

3.4. Texture. Texture is considered an important property used to evaluate the quality of seafood products [12]. In Figure 2(c), we may observe the texture behavior of sierra fillets (control and treatments) stored on ice during 15 days. No statistical differences $(p \geq 0.05)$ were recorded in initial texture between control $(6.7 \pm 1.46)$ and treatments TPE-C $(7.98 \pm 1.00), \mathrm{C}(7.52 \pm 1.33)$, and TPE $(7.27 \pm 1.33)$. These 


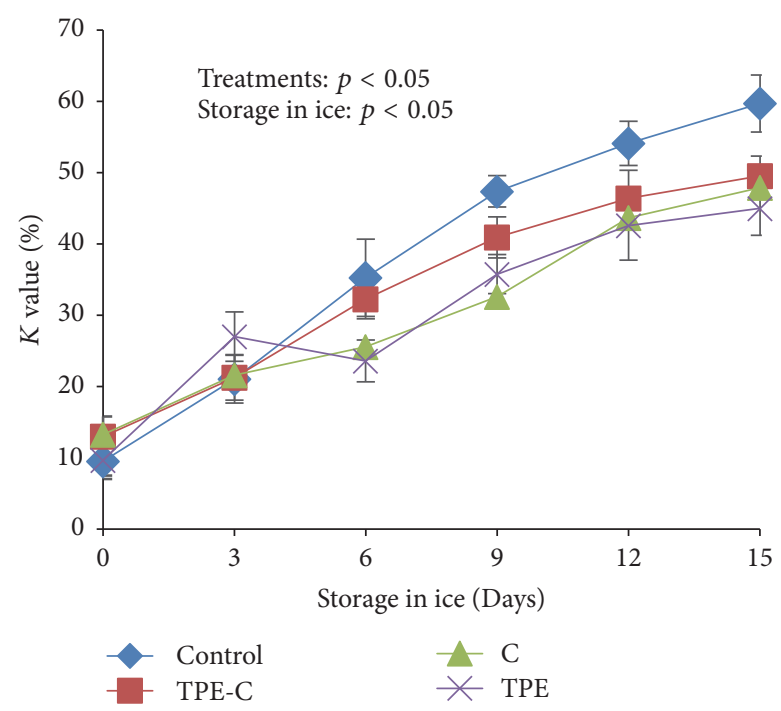

(a)

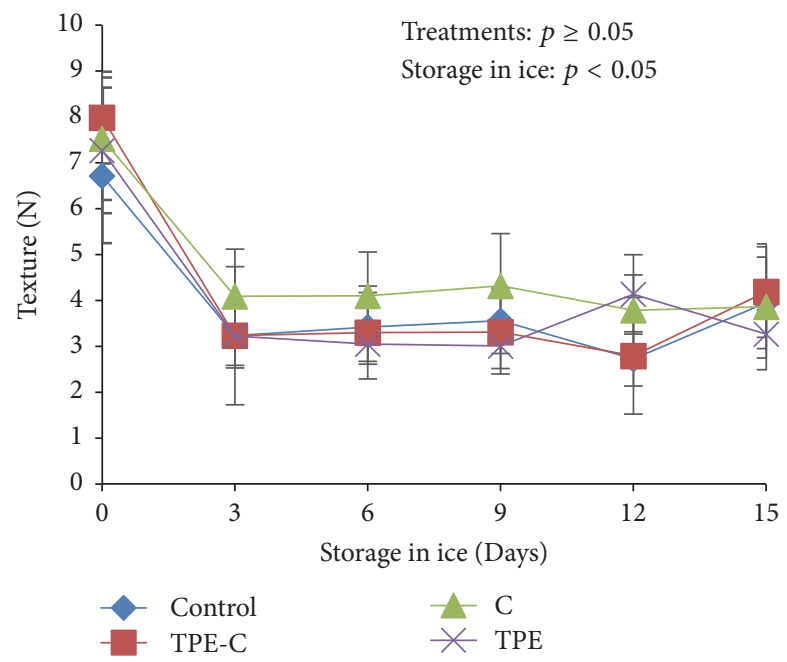

(c)

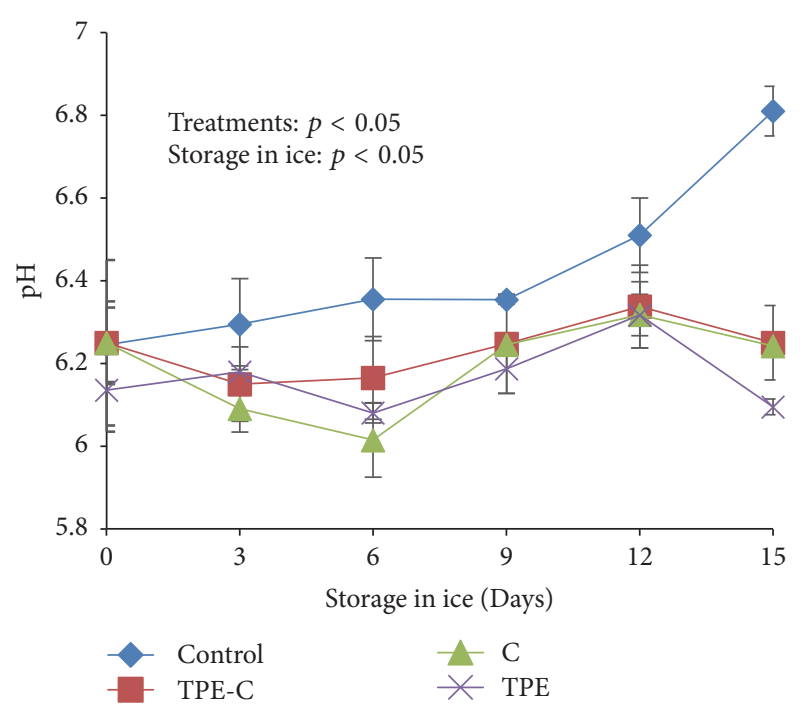

(b)

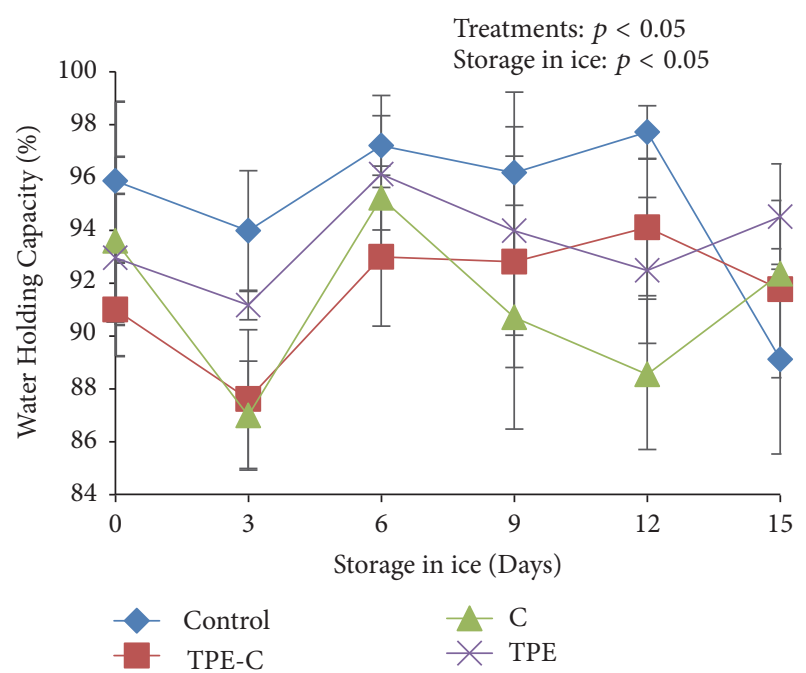

(d)

FIGURE 2: Behavior of $K$ value, $\mathrm{pH}$, texture, and water holding capacity in fillets of sierra (Scomberomorus sierra) with different treatments: (a) control, (b) tomato plan extract, (c) chitosan, and (d) tomato plant extract-chitosan, stored during 15 days in ice. The values are the average of $n=4 \pm$ the standard deviation and stored during 15 days in ice. The values are the average of $n=4 \pm$ the standard deviation.

texture values were similar to those reported by MontoyaCamacho [10] in tilapia (Oreochromis niloticus) muscle: 6.52 \pm $0.22 \mathrm{~N}$. On the other hand, control and treated sierra fillets became significantly $(p<0.05)$ softer after ending icestorage, registering values in the control $3.9 \pm 1.46 \mathrm{~N}$, TPEC $4.2 \pm 1.00 \mathrm{~N}$, C $3.9 \pm 1.33 \mathrm{~N}$, and TPE $3.27 \pm 0.52 \mathrm{~N}$, respectively. Sierra muscle softening can be associated with Z-disc breakdown, actomyosin-complex dissociation, connectin destruction, and collagen denaturation. Also, endogenous proteases can take part in this process by hydrolyzing myofibrillar proteins because the former are active within the $\mathrm{pH}$ range from 5.5 to 6.5 [13], values reaching under experimental conditions. Otherwise, the treatments did not significantly affect $(p \geq 0.05)$ the texture of the sierra fillets.
3.5. Water-Holding Capacity (WHC). WHC is defined as the meat's capacity to retain water molecules during the application of a centrifugal force [14]. In Figure 2(d), we can observe the WHC behavior of sierra fillets, including control and treatments, stored on ice during 15 days. No changes ( $p>$ 0.05 ) in WHC between control and treatments at the beginning of ice-storage were recorded. In this stage, the recorded WHC values (\%) were the following: control, $95.86 \pm 3.00$; TPE-C, $91 \pm 1.77$; C, $93.60 \pm 3.18$; and TPE, $92.95 \pm 2.43$. These latter values were similar to those reported by MontoyaCamacho [10] in tilapia (Oreochromis niloticus) muscle. After the ice-storage experiment ended, a significant $(p<0.05)$ decrease in the WHC of control sierra fillets was recorded, registering values of $89.12 \pm 2.10 \%$, in which water loss could be related with the denaturation of myofibrillar proteins [15]. 

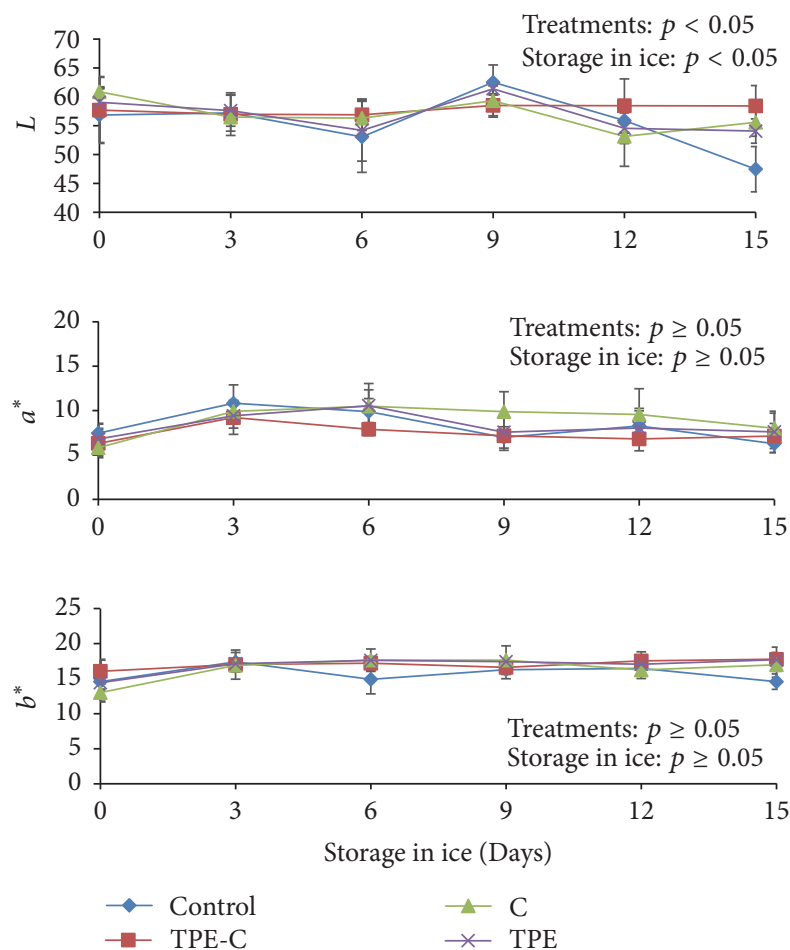

FIgURE 3: Changes in the parameters of color $\left(L, a^{*}\right.$, and $\left.b^{*}\right)$ in fillets of sierra (Scomberomorus sierra) with different treatments: (a) control, (b) tomato plan extract, (c) chitosan, and (d) tomato plant extract-chitosan, stored during 15 days in ice. The values are the average of $n=4 \pm$ the standard deviation, stored during 15 days in ice. The values are the average of $n=4 \pm$ the standard deviation.

The WHC test has been employed as a quality indicator of fish muscle, and its decrease throughout storage can be related to muscle softening, precisely as what occurred in the present experiment. Otherwise, no significant differences $(p<0.05)$ among the treatments were recorded.

3.6. Color. Consumers consider color an important sensorial attribute for determining the acceptability of fish products. Figure 3 depicts $L^{*}, a^{*}$, and $b^{*}$ values obtained from the control and treated sierra fillets. $L^{*}$ parameter revealed initial values of $56.76 \pm 4.81,57.60 \pm 1.07,60.78 \pm 2.55$, and $58.96 \pm$ 2.40 for control, TPE-C, C, and TPE, respectively, whereas, at the end of storage-on-ice, these values changed to $47.43 \pm$ $3.90,58.34 \pm 3.51,55.52 \pm 2.41$, and $54.01 \pm 2.10$ in the same order. Only the control sierra fillets underwent a significant $(p<0.05)$ decrease in $L^{*}$ during storage; thus, their whiteness and quality loss were reflected. Sierra fillets treated with TPE-C, C, and TPE demonstrated greater whiteness than the control, therefore confirming the protective effect of tomato plant extract in whole form or blended with chitosan. On the other hand, the application of different treatments on the sierra fillets did not induce $(p \geq 0.05)$ changes in $a^{*}$ and $b^{*}$ parameters, nor with respect to storage time. Hence, the color of the sierra fillets tended toward yellow-orange in the color sphere, recording hue values ranging between 62.90 and 68.57 .

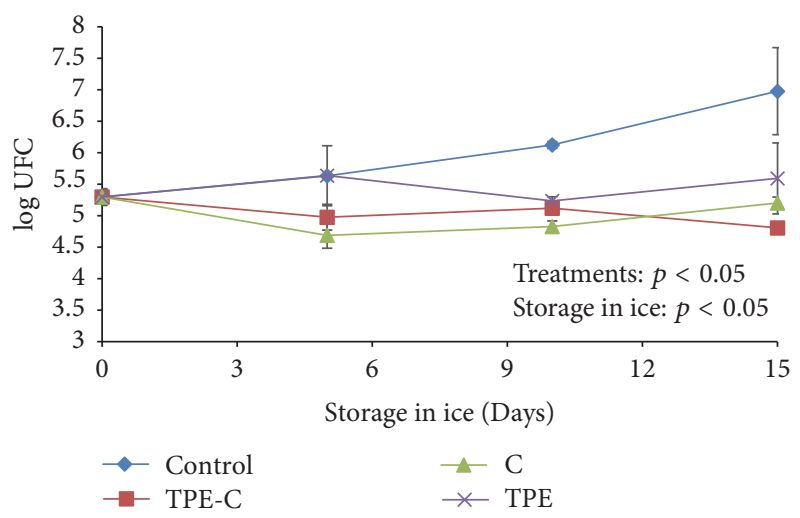

FIGURE 4: Microbiological changes in sierra fillets (Scomberomorus sierra) with different treatments: (a) control, (b) tomato plan extract, (c) chitosan, and (d) tomato plant extract-chitosan, stored during 15 days in ice. The values are the average of $n=4 \pm$ the standard deviation.

3.7. Microbiologic Quality. In Figure 4, one can observe the mesophyll count of sierra fillets, control, and treatments, stored on ice during 15 days. At the beginning of the storage, the registered bacterial counts were, in control $5.30 \pm 0.13$, in TPE-C $4.95 \pm 0.24$, in C $5.21 \pm 0.52$, and in TPE 5.13 $\pm 0.47 \log$ Colony-Forming Units $(\mathrm{CFU}) / \mathrm{g}$, respectively. No statistical differences $(p \geq 0.05)$ among all of the treatments were recorded. After the ice-storage experiment terminated, we observed a significant $(p<0.05)$ increasing the bacterial count of control fillets, demonstrating values of $6.98 \pm$ $0.69 \log \mathrm{CFU} / g$. Notably, treatments TPE-C (4.81 $\pm 0.10 \mathrm{log}$ $\mathrm{CFU} / \mathrm{g}), \mathrm{C}(5.20 \pm 0.44 \mathrm{log} \mathrm{CFU} / \mathrm{g})$, and TPE (5.59 $\pm 0.56 \mathrm{log}$ $\mathrm{CFU} / \mathrm{g})$ were capable of delaying significantly $(p<0.05)$ the bacterial growth. The latter evidenced the potentiality of tomato plant extract, alone or in combination with chitosan, as an antibacterial agent to extend the shelf life of sierra fillets. The results point to TPE-C as best antimicrobial treatment, which could be related with a synergism between tomato plant extract and chitosan. As noted, tomato plant extract contributes to delaying bacterial growth, as well as also retaining quality and extending the shelf life of sierra fillets.

\section{Conclusion}

The application of ethanolic tomato plant extract blended with a chitosan edible coating extended, for at least 5 days, the shelf life of sierra fillets stored on ice due to their antimicrobial power. However, future researches require their being directed toward the identification of antimicrobial compounds present in this tomato plant extract.

\section{Conflicts of Interest}

All authors declare that there are no conflicts of interest regarding the publication of this paper.

\section{References}

[1] L. Iturriaga, I. Olabarrieta, and I. M. de Marañón, "Antimicrobial assays of natural extracts and their inhibitory effect against 
Listeria innocua and fish spoilage bacteria, after incorporation into biopolymer edible films," International Journal of Food Microbiology, vol. 158, no. 1, pp. 58-64, 2012.

[2] A. Rajalakshmi, N. Krithiga, and A. Jayachitra, "Antioxidant activity of the chitosan extracted from shrimp exoskeleton," Middle East Journal of Scientific Research, vol. 16, no. 10, pp. 1446-1451, 2013.

[3] N. P. Silva-Beltrán, S. Ruiz-Cruz, C. Chaidez et al., "Chemical constitution and effect of extracts of tomato plants byproducts on the enteric viral surrogates," International Journal of Environmental Health Research, vol. 25, no. 3, pp. 299-331, 2015.

[4] J. M. Ryder, "Determination of adenosine triphosphate and its breakdown products in fish muscle by high-performance liquid chromatography," Journal of Agricultural and Food Chemistry, vol. 33, no. 4, pp. 678-680, 1985.

[5] A. Sagedhal, J. P. Busalmen, H. A. Roldán, M. E. Paredi, and M. Crupkin, "Post-mortem changes in adenosine triphosphate and related compounds in mantle of squid (Illex argentinus) at different stages of sexual maturation," Journal of Aquatic Food Product Technology, vol. 6, no. 4, pp. 43-56, 1997.

[6] A. D. Woyewoda, S. J. Shaw, P. J. Ke, and B. G. Burns, "Recommended laboratory methods for assessment of fish quality," Tech. Rep., Nova, Scotia, Canada, 1986, Canadian Technical Report of Fisheries and Aquatic Sciences.

[7] C. S. Cheng, O. O. Hamann, N. B. Webb, and V. Sidwell, "Effects of species and storage time on minced fish gel texture," Journal of Food Science, vol. 44, no. 4, pp. 1087-1092, 1979.

[8] Norma Oficial Mexicana, "Método para la cuenta de bacterias aerobias en placa," Tech. Rep. NOM-092-SSA1-1994, Diario Oficial de la Federación, 1994.

[9] F. J. Castillo-Yáñez, R. Pacheco-Aguilar, E. Márquez-Ríos, M. E. Lugo-Sánchez, and J. Lozano-Taylor, "Freshness loss in sierra fish (scomberomorus sierra) muscle stored in ICE as affected by postcapture handling practices," Journal of Food Biochemistry, vol. 31, no. 1, pp. 56-67, 2007.

[10] N. Montoya-Camacho, Efecto de la temperatura de almacenamiento sobre el rigor mortis y la calidad del músculo de tilapia Oreochromis niloticus [M.S. thesis], Universidad de Sonora, Hermosillo, Sonora, México, 2013.

[11] S. Liu, W. Fan, S. Zhong et al., "Quality evaluation of tray-packed tilapia fillets stored at $0 \circ \mathrm{C}$ based on sensory, microbiological, biochemical and physical attributes," African Journal of Biotechnology, vol. 9, no. 5, pp. 692-701, 2010.

[12] S. Pornrat, T. Sumate, S. Rommanee, K. Sumolaya, and W. L. Kerr, "Changes in the ultrastructure and texture of prawn muscle (Macrobrachuim rosenbergii) during cold storage," LWT- Food Science and Technology, vol. 40, no. 10, pp. 1747-1754, 2007.

[13] I. N. A. Ashie, J. P. Smith, and B. K. Simpson, "Spoilage and Shelf-Life Extension of Fresh Fish and Shellfish," Critical Reviews in Food Science and Nutrition, vol. 36, no. 1-2, pp. 87121, 1996.

[14] G. B. Olsson, R. Ofstad, J. B. Lødemel, and R. L. Olsen, "Changes in water-holding capacity of halibut muscle during cold storage," LWT- Food Science and Technology, vol. 36, no. 8, pp. 771-778, 2003.

[15] V. M. Ocaño-Higuera, E. Marquez-Ríos, M. Canizales-Dávila et al., "Postmortem changes in cazon fish muscle stored on ice," Food Chemistry, vol. 116, no. 4, pp. 933-938, 2009. 

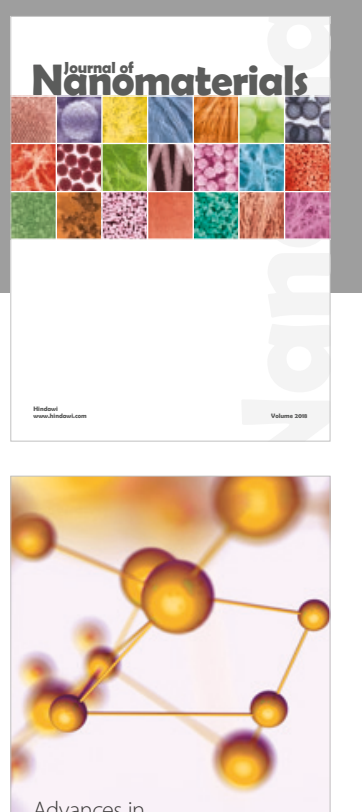

Physical Chemistry
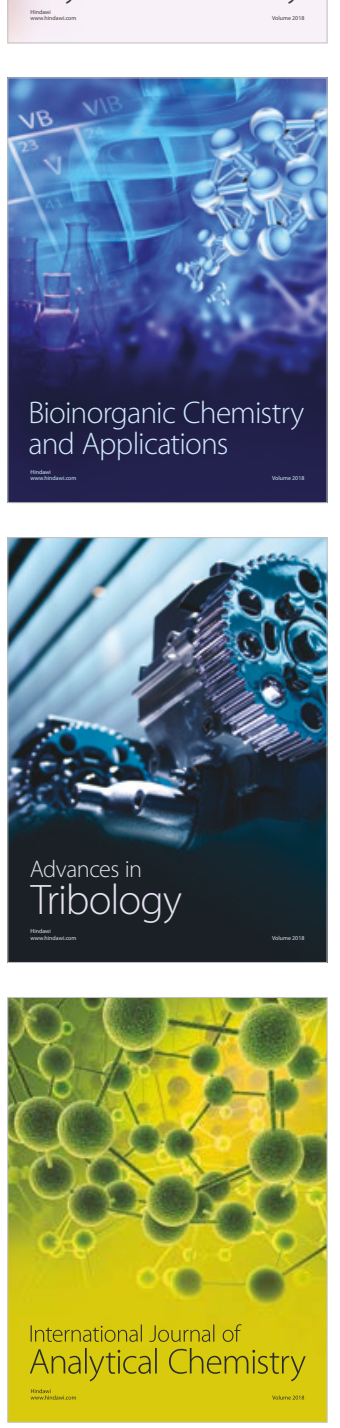

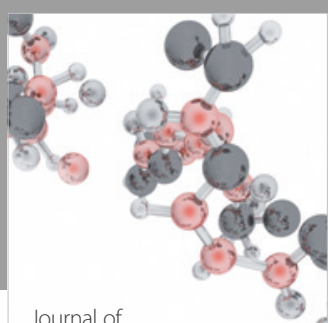

Analytical Methods

in Chemistry

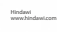

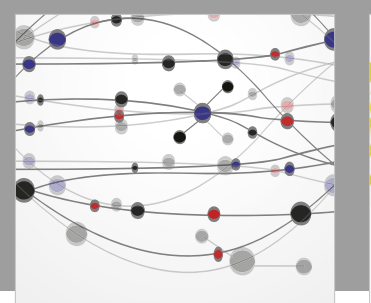

The Scientific World Journal

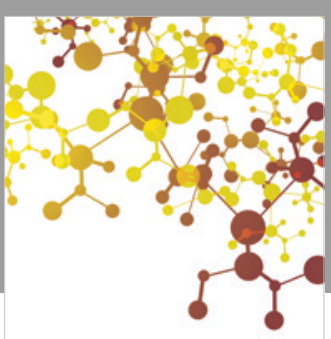

Journal of

Applied Chemistry
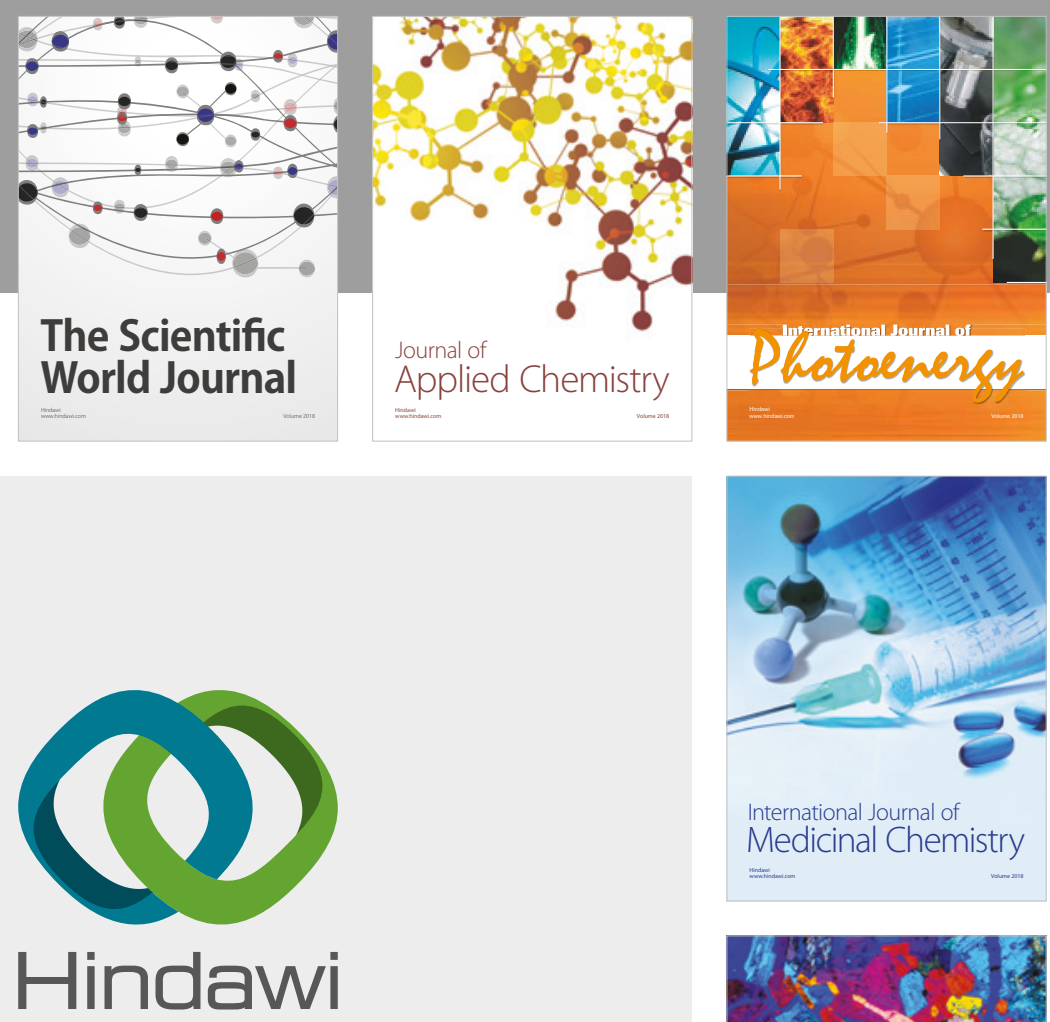

Submit your manuscripts at

www.hindawi.com
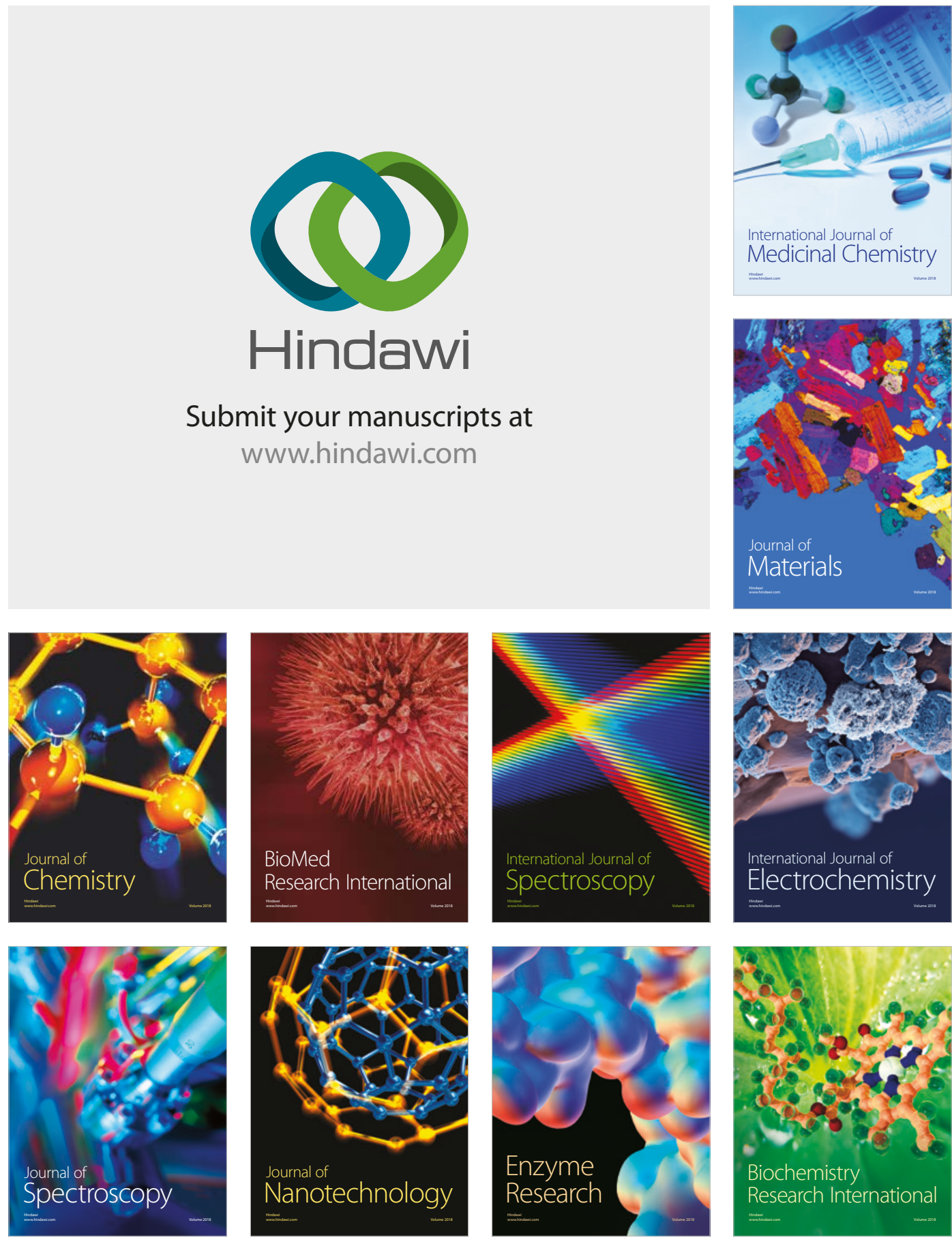
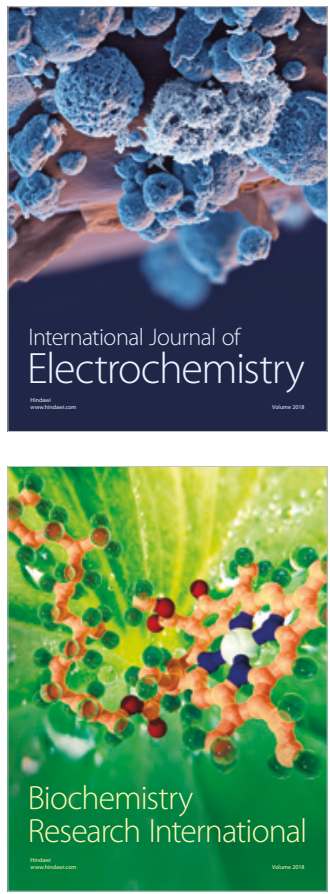